\title{
Evaluation of cultural creative industry efficiency in Dalian based on
}

\author{
DEA model \\ Xiaonan Fan, Mengmeng Sun * \\ Dalian Polytechnic University, China \\ Corresponding author: Sun Mengmeng,postgraduate Student, 931500596@qq.com
}

\begin{abstract}
Based on the theory of data envelopment analysis (DEA) model, this paper selected ten cities as study samples, and studied their input and output index values of cultural creative industries in $20^{1} 4$. Firstly, it builds a culture of evaluation index system from city level, and next evaluates the efficiency of the cultural creative industries of Dalian. The result shows that cultural creative industry park in Dalian lacks efficient planning, cultural creative enterprises and brand are in lack of independent innovation, creative talent cultivation mechanism is lacking, and scientific researchers are not only less and in low conversion rate.
\end{abstract}

Key words: DEA method; creative industry; efficiency evaluation

\section{Introduction}

With the rapid development of economic globalization and the creative economy, as the international division of labor and industrial value chain, cultural creative industry is booming. In recent years, Liaoning province clearly put forward the development strategy of "cultural province", and promoted cultural creative industries as an important direction of development. Dalian as an abundant innovative resource in Liaoning province is the national culture and technology integration demonstration base. In 2014, Dalian has nearly 800 thousand people engaged in cultural creative industries, and there are more than 30 thousand of cultural corporate units, and the total output is $\$ 351$ billion 720 million with an increase of $7.2 \%$ over the previous year. In 2014, Dalian realized an increase of $\$ 75$ billion 640 million, which accounting for GDP of $8.26 \%{ }^{1}$. But with the development of cultural creative industries in Dalian, it had low efficiency. In order to promote the efficient development of cultural creative industries, Dalian should improve the technology, talent, capital, policy and other elements of the utilization rate. The paper is based on the DEA theory model, to build a 
culture of evaluation index system from city level, and to evaluate the efficiency of the cultural creative industries of Dalian. The paper analyzes the reasons for the low efficiency of the cultural creative industries in Dalian from two aspects of input and output, and puts forward some countermeasures and suggestions to improve the efficiency of the cultural creative industries in Dalian.

\section{Research methods}

Data envelopment analysis (DEA) is a new method to analysis the effective system on the basis of "efficiency evaluation" concept, which is developed by famous scientist A.Charnes, W.W.Cooper and other scholars ${ }^{2}$. Since the first DEA model-- ${ }^{2} \mathrm{R}$ model (also known as the CCR model) was established in 1978, the related theoretical research is deepening and the application field is more and more extensive. This model is suitable for the performance evaluation of multi objective decision making unit with multi input and output, and this method is based on the decision making unit (Decision Making Unit, referred to as DMU). By means of mathematical programming model, all decision making units are projected to the DEA frontier, and compare with the extent to which DMU deviates from the frontier of DEA production. Finally, the relative validity of the decision units is evaluated by using comprehensive performance evaluation.

In the empirical research, the main choice of measurement model is $C^{2} R$.

Model simplified to ${ }^{3}$

$$
\left\{\begin{array}{l}
\min \left[\theta-\left(\hat{e}^{T} s^{-}+e^{T} s^{+}\right)\right] \\
s . t \cdot \sum_{j=1}^{n} X_{j} \lambda_{j}+s^{-}=\theta X_{0} \\
\sum_{j=1}^{n} Y_{j} \lambda-s^{+}=Y_{0} \\
\lambda_{j} \geq 0, j=1,2, \ldots, n \\
s^{+} \geq 0, s^{-} \geq 0
\end{array}\right\}
$$

\section{Variable selection and data sources}

\subsection{Variable selection}

At present, the domestic and overseas evaluation indexes are China's urban creative index, European creative index, Shanghai urban creative index, Beijing urban creative index, and CCCI model ${ }^{4}$. This article mainly carries on the research based on these 5 indexes, and simultaneously takes into consideration the related situation of the development of Dalian's 
cultural creative industries, as well as the availability and operability of the data. This paper is based on the $3 \mathrm{~T}$ theory of Richard Florida ${ }^{5}$, from the two aspects of input and output. We select the appropriate indicators to evaluate the efficiency of cultural creative industries in Dalian, as table 1 shows.

Table 1 - Dalian cultural creative industries efficiency evaluation index system

\begin{tabular}{|l|l|}
\hline Pointer Type & \multicolumn{1}{|c|}{ Forming Index } \\
\hline Input & Number of cultural creative industries parks \\
\hline & Proportion of cultural creative enterprise \\
\hline & Proportion of creative class \\
\hline & Proportion of R\&D expenditure \\
\hline & Quantities of patent application \\
\hline & Per capita GDP \\
\hline Output & Proportion of cultural creative industries in added value \\
\hline
\end{tabular}

\subsection{Data sources}

This paper selected Dalian, Beijing, Shanghai, Hangzhou, Xi'an, Suzhou, Xiamen, Tianjin, Qingdao and Shenyang as research samples, by using their annual report, China cultural creative Industries Development Report in 2014, and Cultural Creative Industries Association website to access to their cultural creative industries input and output indicators in 2014, as table 2 shows.

Table 2- Value index of input and output of cultural creative industries

\begin{tabular}{|l|l|l|l|l|l|l|c|}
\hline City & $\begin{array}{l}\text { Value } \\
\text { added ratio }\end{array}$ & $\begin{array}{l}\text { Quantities } \\
\text { of parks }\end{array}$ & $\begin{array}{l}\text { Enterprise } \\
\text { number ratio }\end{array}$ & $\begin{array}{l}\text { employees } \\
\text { ratio }\end{array}$ & $\begin{array}{l}\text { R\&D/ } \\
\text { GDP }\end{array}$ & $\begin{array}{l}\text { Quantities } \\
\text { of patent }\end{array}$ & $\begin{array}{c}\text { Per capita } \\
\text { GDP }\end{array}$ \\
\hline Dalian & 0.09 & 32 & 0.26 & 0.16 & 0.020 & 15241 & 77097 \\
\hline Shanghai & 0.13 & 108 & 0.21 & 0.29 & 0.034 & 67639 & 73297 \\
\hline Tianjin & 0.12 & 52 & 0.2 & 0.15 & 0.025 & 11090 & 70402 \\
\hline Hangzhou & 0.32 & 41 & 0.27 & 0.17 & 0.029 & 43179 & 68340 \\
\hline Suzhou & 0.42 & 29 & 0.31 & 0.17 & 0.025 & 19631 & 85993 \\
\hline Xiamen & 0.2 & 37 & 0.21 & 0.15 & 0.027 & 9089 & 58157 \\
\hline Qingdao & 0.1 & 29 & 0.22 & 0.17 & 0.022 & 16731 & 65016 \\
\hline Xi'an & 0.22 & 23 & 0.13 & 0.12 & 0.011 & 7467 & 38280 \\
\hline Beijing & 0.33 & 69 & 0.36 & 0.39 & 0.079 & 138111 & 70251 \\
\hline Shenyang & 0.07 & 19 & 0.17 & 0.15 & 0.010 & 11784 & 61891 \\
\hline
\end{tabular}




\section{Empirical results}

\subsection{Aggregate analysis}

Applying software DEAP 2.1, processing the collected data, and the evaluation results of each decision unit $\mathrm{C}^{2} \mathrm{R}$ model are obtained, as table 3 shows.

Table 3 - Evaluation results of every decision unit model

\begin{tabular}{|c|c|c|c|c|}
\hline Decision package & Overall efficiency & Pure technical efficiency & Scale efficiency & Return of scale \\
\hline Dalian & 0.347 & 0.824 & 0.421 & irs \\
\hline Shanghai & 0.366 & 0.619 & 0.591 & irs \\
\hline Tianjin & 0.405 & 0.800 & 0.507 & irs \\
\hline Hangzhou & 0.899 & 0.909 & 0.978 & drs \\
\hline Suzhou & 1.000 & 1.000 & 1.000 & crs \\
\hline Xiamen & 0.747 & 0.822 & 0.909 & irs \\
\hline Qingdao & 0.301 & 0.755 & 0.399 & irs \\
\hline Xi'an & 1.000 & 1.000 & 1.000 & crs \\
\hline Beijing & 0.817 & 0.918 & 0.890 & drs \\
\hline Shenyang & 0.445 & 1.000 & 0.445 & irs \\
\hline Mean Value & 0.623 & 0.865 & 0.704 & - \\
\hline
\end{tabular}

Table 4 -Efficiency analysis of cultural creative industries in Dalian

\begin{tabular}{|c|c|c|c|c|}
\hline Variable & Original value & Output deficiency & Output deficiency rate & Target value \\
\hline Output 1 & 0.090 & 0.071 & $78 \%$ & 0.161 \\
\hline Variable & Original value & Input redundancy & Input redundancy rate & Target value \\
\hline Input 1 & 32.000 & 10.577 & $33 \%$ & 21.423 \\
\hline Input 2 & 0.260 & 0.114 & $44 \%$ & 0.146 \\
\hline Input 3 & 0.160 & 0.028 & $18 \%$ & 0.132 \\
\hline Input 4 & 0.020 & 0.01 & $50 \%$ & 0.011 \\
\hline Input 5 & 15241.000 & 6071.521 & $40 \%$ & 9169.479 \\
\hline Input 6 & 77097.000 & 29505.619 & $38 \%$ & 47591.380 \\
\hline
\end{tabular}

On the basis of table 3, the average efficiency of this 10 samples of urban cultural creative industries is 0.623 , the average efficiency of pure technology is 0.865 , and the scale efficiency average is 0.704 , which shows that the overall efficiency of these 10 urban cultural industries is not high, at the same time, pure technical efficiency is higher than scale efficiency.

Among the selected cities, the cities with comprehensive efficiency of 1 are only Suzhou and Xi'an, which are at the forefront of the technical efficiency. The comprehensive efficiency of Dalian is only 0.347, which shows that the development of cultural creative industries in Dalian has greater room for improvement. From the purely technical efficiency point of view, 
Dalian is below average. From the scale point of view, in addition to Suzhou and Xi'an, the rest of the city are decreasing returns to scale or increasing trend in non effective stage, besides Dalian is in the stage of increasing returns to scale.

In order to evaluate the efficiency of cultural creative industries in Dalian better, we get further efficiency analysis through DEAP 2.1, as table 4 shows.

\subsection{Specific comparative analysis}

\subsubsection{Output}

The ratio of GDP added value of cultural creative industries in Dalian is 0.090, output value is 0.071 , output deficiency rate is as high as $78 \%$, which means under the existing investment conditions, the cultural creative industries have not reached the best level of output, so we need to adjust the proportion of the existing resources, so as to increase the value of cultural creative industries and improve efficiency.

\subsubsection{Input}

The original value of cultural creative industry parks in Dalian is 32, the target value is 21 , and the redundant value is 11 . Among the 10 sample cities, Dalian is in the middle and lower levels in the construction of cultural creative parks. As far as the number of existing parks is concerned, the total quantity is not only small, but the input and output have not reached the optimum scale. The number of redundant parks in Shanghai is as high as 41 , which means that the large number of parks does not mean maximum efficiency. Firstly, almost all new creative industrial parks have spent a lot of money in the external decoration, but ignore the protection of the creative source ${ }^{8}$. Secondly, there is homogeneous competition between the parks, and the similar types of parks are relatively close. Thirdly, Dalian's key areas of cultural creative industries have become a cultural industry cluster after several years of development ${ }^{9}$.

The number of cultural and creative enterprises in Dalian and the number of urban enterprises is 0.146 , and the redundancy rate is $44 \%$, only after the most adjusted amount of Beijing. In fact, the lack of independent research and development ability of Dalian cultural creative enterprises brings out this inefficient phenomenon.

The initial ratio of creative class and urban employees in Dalian is 0.160 , the optimal scale is 0.132, and the redundancy rate is $18 \%$. Compared with the better developed city--Hangzhou, it needs to be improved. This situation shows that the total number of people engaged in cultural creative industries in Dalian is relatively large, but there is a lack of excellent talents with complete professional skills.

In 2014, R\&D expenditure in Dalian accounted for 2\% of the city's GDP, redundant value is 0.01 , and redundancy rate is $50 \%$, far greater than Tianjin and other cities. Under the new 
normal, Dalian innovation drive capability has steadily improved, but the R\&D investment intensity needs to be further improved, and the level of production, research and production needs to be further improved.

\section{Conclusions and suggestions}

\subsection{Brief summaries}

Through the above analysis and evaluation of the efficiency of cultural creative industries in Dalian, and compared with the index efficiency of the sample cities, the reasons for this inefficient development of cultural creative industries in Dalian are as follows.

- Cultural creative industry parks lack efficient construction planning.

- Cultural creative enterprises and brands lack independent innovation.

- Lack of creative talents cultivation mechanism.

- Scientific research results are few and the rate of scientific research achievement conversion is low.

\subsection{Suggestions}

\subsubsection{Effectively planning for Cultural Creative Industries Park}

In the existing industrial park, according to the actual situation, combing with all kinds of parks, and improving existing resources integration efficiency. In the future construction of the park, Dalian should avoid duplication and homogeneity of the park. Secondly, we should combine the renovation and construction of the surrounding communities, and build the "creative community" which embodies the characteristics of Dalian ${ }^{10}$.

\subsubsection{Enhancing the creative ability of cultural creative industries}

Globalization can make cultural creation cross industry and regional flow, so as to maximize the cultural influence. Take Dalian 15 warehouse as an example, it is a key project carefully nurtured by the Dalian municipal government. In order to make it into an international first-class Park, we should start from many aspects of transformation. The government should extend the humanistic context of the city, improve the cultural quality of the city, and develop Donggang District into a number of industrial clusters ${ }^{11}$.

\subsubsection{Improving the conversion rate of patented technology}

Dalian should improve the conversion rate of the patent technology, essential for the perfection of laws and regulations. First, popularize the knowledge of intellectual property to the public; actively promote the existing cultural creative industries. In second, the 
government should vigorously promote to protect intellectual property, clarify the application process, and highlight the timeliness ${ }^{12}$. Third, we should establish and improve laws and regulations, strengthen the supervision, and resolutely combat all kinds of violations, by using this to protect property rights of the legitimate rights of people.

\section{Acknowledgements}

This work has been partially funded by Liaoning Provincial Department of education project (project number is W2015053), Liaoning provincial education department education research management think tank project (project number is ZK2015088), Liaoning society of science and technology joint project (project number is 2016lsljdwtzdian-03), Institute of higher education in Liaoning Province in "13th Five-Year planning" project (project number is GHYB160102), Dalian society of science and technology joint project (project number is 2016dlskyb112).

\section{References}

1. China cultural creative Industries Development Report in 2014[R]. Beijing: China Economic Publishing House. 2015:4-6.

2. Charnes, W. W. Cooper. Invariant multiplicative efficiency and piece wise Cobb—Douglas envelopment. Ops Res Lett, 1985, 2(3): 101-103.

3. Zhang Jingcheng. China Creative Industry Development Report (2013) [R]. Beijing: China Economic Publishing House. 2014:7-14.

4. Chen Ying, Gong Xue, Gao Changchun. Comparison and analysis of global creative index [J]. Soft Science. 2013(12): 30—33.

5. Guo Yong, Hao Yuanxiao. Theoretical model and measurement index system of creative index in China [J]. Industrial Economy.2006(1)1l - 13.

6. Xiao Yongliang, Jiang Zhenyu. Research on Creative cities and Creativity Index [J]. Journal of Tongji University. 2013(6):7

7. Li Zheng, Fu Chunyu. China's creative economy development policy and its effect [J]. Economist. 2012.23:52-61.

8. Hu Dongxue, Pan Qinhua. Evaluation research on the competitiveness of Shanghai cultural and creative industries based on the diamond model [J]. Shanghai Management Science. 2009(1): 33-37.

9. Wang Tiejun. The Economics of Ideas [M]. China Financial Publishing House. 2012 (11): 34-39. 
10. Jin Yuanpu. The rise of contemporary cultural and creative industries [M]. Haitian Press, 2003:102.

11. Xu Peng. Research on the efficiency of logistics industry in Liaoning Province Based on DEA [D]. Dalian: Dalian Maritime University. 2012:12.

12. Zhang Weihong. Research on the efficiency of China's real estate industry based on DEA [J]. Industry Development Forum (Building Economy). 2012:6. 